\title{
Evaluation of the City Emergency Capacity Based on the Evidence Theory
}

\author{
Jiang-hua Zhang, ${ }^{1}$ Wen-hui Huang, ${ }^{2}$ and Jin $\mathrm{Xu}^{3}$ \\ ${ }^{1}$ School of Management, Shandong University, Jinan, Shandong 250100, China \\ ${ }^{2}$ School of Management, University of Chinese Academy of Sciences, Beijing 100049, China \\ ${ }^{3}$ School of Mathematics, Shandong University, Jinan, Shandong 250100, China
}

Correspondence should be addressed to Jiang-hua Zhang; zhangjianghua28@gmail.com

Received 5 September 2013; Accepted 24 October 2013

Academic Editor: Yuxin Mao

Copyright (C) 2013 Jiang-hua Zhang et al. This is an open access article distributed under the Creative Commons Attribution License, which permits unrestricted use, distribution, and reproduction in any medium, provided the original work is properly cited.

\begin{abstract}
The evidence theory is a decision-making method used to solve incomplete information and uncertain problems. This paper proposes to use evidence theory to evaluate city emergency capacity on the basis of the existing evaluation system. And when scoring each index, experts give the trust degrees of different evaluation ranks, including the trust degrees that cannot be given. It can be seen from this study that the application of evidence theory in city emergency capability evaluation has its feasibility and superiority.
\end{abstract}

\section{Introduction}

In the 21st century, a variety of unexpected accidents occur frequently, along with the ever-accelerating process of urbanization, testing the city emergency response capacity. American "9.11" incident in 2001 sounded the alarm to the world's countries, and city emergency response capacity construction is on the agenda. City emergency capability refers to the capabilities of disaster prevention and mitigation when dealing with the possible disasters and accidents of manpower, technology, organization, and resource in a city, which also refers to the comprehensive disposal abilities of a city on unexpected disasters during the entire process. With the expansion of human activity and the improvement of the modernization, the impact of the unexpected disasters on city economic development, social stability, and public safety is becoming more and more serious. As to social management and public service, the government has the responsibility of dealing with emergencies, protecting people's lives and property, and safeguarding the public security. But the 2008 Wenchuan earthquake in China, the 3.11 earthquakes in Japan, the 2012 "Sandy" hurricane in the United States, and a series of city disasters, have exposed the disadvantage of the government administration in dealing with emergency disasters, which directly or indirectly affect the disaster relief activities. Therefore, in order to better cope with sudden disasters and accidents, it is necessary to strengthen the research of city emergency response capacity.

\section{Evaluation Index System of City Emergency Capacity and Method Reviews}

Carrying out emergency capacity assessment is the basis work of strengthening city disaster emergency management, and it is a motivation for the government to improve emergency management capabilities. In recent years, various national, regional governments, and academics have made many contributions on establishing the city emergency evaluation index system and methods.

The United States is one of the countries to first study the city emergency capability and is currently walking in the forefront of this field. It established a comprehensive evaluation index system which has been widely referred to as the standard on a global scale. In June 1997, the Federal Emergency Management Agency (FEMA) and the National Emergency Management Association (NEMA) jointly proposed a set of capability assessment for readiness (CAR) [1], including 13 
emergency management functions, 209 attributes, and 1014 evaluation indexes. In addition, state and local governments also set 5-8 different indexes to evaluate their city emergency capacities, such as the command and management, emergency preparedness, resource management, communications and information management, and supporting technologies.

Japan is located in the Western Pacific volcanic seismic belt, and is a multivolcano and earthquake-prone country. Therefore, establishing the city emergency capacity is particularly important to this island nation. Japan's emergency capacity index system adopted "four-level" government disaster emergency system and disaster emergency assistance system. The "four-level" disaster emergency systems include central government disaster response, local government disaster response, community disaster response, and residents' associations and self-help disaster education. Disaster emergency assistance systems include disaster emergency preparedness system, disaster emergency information systems, and disaster emergency government and social forces alliance system [2]. Especially after the Great Hanshin earthquake, the original emergency management plans were modified by the Japanese local governments in order to accommodate the city emergency management needs. They conducted a comprehensive analysis and assessment on the local government's emergency management in accordance with the emergency command, emergency information systems, refuge facilities, and storage of relief supplies, emergency medical system, and other 39 projects.

Taiwan area's disaster emergency capability evaluation sets different systems according to different objects. Its emergency work performance has eleven major categories, including general, disaster potential analysis, distribution of relief resources, disaster response units for each stage of the division of labor and responsibilities, disaster case investigation and analysis, storm and flood emergency response, earthquake emergency response, disaster response common to other types of measures, disaster management, attachments, and others [3].

Because urbanization in China started late, the city emergency capacity is gradually taken seriously in recent years. Now, it has formed management system and corresponding legal norms, but it still needs scientific and effective evaluation index system and evaluation methods. Deng et al. [4] first propose the city emergency capability assessment system framework in China, including 18 classes, 76 properties, and 405 features, which comprehensively reflected all aspects of the current city emergency capacity. Zhang et al. [5] refer the U.S. Federal Emergency Management Agency (FEMA), building the city emergency capacity evaluation index system and using the fuzzy AHP to determine the weight of each index. Cheng et al. [6] change the analysis of assessment index system from qualitative analysis to quantitative analysis with the application of SEM and analyze relations of each index. X.-T. Wu and L.-P. Wu [7] build the evaluation system and a comprehensive evaluation model to the fire emergency capability in city community based on the fuzzy analytic hierarchy process. Wang et al. [8] use logistic curve alternative, the traditional linear curve analysis, and the city
TABLE 1: The evaluation index system of emergency capability.

\begin{tabular}{|c|c|c|}
\hline Target layer & $\begin{array}{l}\text { Primary } \\
\text { indexes }\end{array}$ & Secondary indexes \\
\hline \multirow{3}{*}{$\begin{array}{l}\text { City } \\
\text { emergency } \\
\text { capability }\end{array}$} & $\begin{array}{l}\text { Predisaster } \\
\text { crisis } \\
\text { prevention } \\
\text { and early- } \\
\text { warning } \\
\text { capabilities }\end{array}$ & $\begin{array}{l}\text { The law and the plan establishment } \\
\text { Monitoring and early-warning } \\
\text { The emergency management } \\
\text { organizations } \\
\text { Training, exercises, and education }\end{array}$ \\
\hline & $\begin{array}{l}\text { Disaster } \\
\text { response and } \\
\text { disposal } \\
\text { capabilities }\end{array}$ & $\begin{array}{l}\text { Risk analysis and other emergency } \\
\text { response systems } \\
\text { Professional teams and volunteers } \\
\text { Command, control, and } \\
\text { communications on the scene } \\
\text { Planning and management of } \\
\text { logistics }\end{array}$ \\
\hline & $\begin{array}{l}\text { Postdisaster } \\
\text { recovery and } \\
\text { reconstruc- } \\
\text { tion } \\
\text { capabilities }\end{array}$ & $\begin{array}{l}\text { Postdisposal } \\
\text { Funds to support recovery and } \\
\text { reconstruction }\end{array}$ \\
\hline
\end{tabular}

emergency capability development process and propose the city emergency capability assessment model based on logistic curve.

In addition, Simpson [9] uses a number of research methods, including case studies, observation, surveys, and interviews to study neighborhood and local emergency capability, which are applied to several fields of inquiry, including neighborhood and community planning and nature hazards, in particular earthquakes. Simonoff et al. [10] present a risk-based approach that can potentially be used to help emergency planners to improve the capabilities of public safety organizations to respond to terrorist attacks, accidents, or natural disasters. Ju et al. [11] present a hybrid fuzzy method consisting of FAHP and a 2-tuple fuzzy linguistic approach to evaluate emergency capacity.

But so far, there is not a unified, comprehensive mathematical theory for city emergency capacity evaluation. According to people's understanding on the evidence and knowledge, the evidence theory ( $D-S$ theory) gives uncertainty measure for the uncertain events, which can be better to deal with the fuzzy and uncertain information synthesis problem. This paper will use the evaluation index system and weight in the literature [5], as shown in Table 1. We will try to use $D-S$ theory to make the evaluation of city emergency capacity, hoping to provide a theoretical basis for city emergency capacity.

\section{Evidence Theory}

In 1968, Dempster discussed the problem of statistical reasoning generalization and provided the synthesis principle of two groups of evidence (i.e., two independent information sources) in the book "A Generalization of Bayesian Inference." On this basis, Shafer published the book "The Mathematical Theory of Evidence" in 1976, announcing the birth of the evidence theory, which is also called the $D-S$ theory $[12,13]$. 


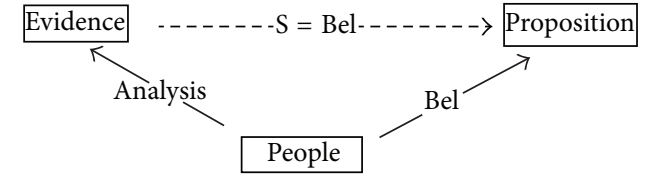

FIGURE 1: The constructive explanation of probability.

Evidence theory is the ideal method to solve the uncertainty problem, and it causes wide interest in the artificial intelligence field. Evidence theory has a good application in target recognition, the military command, comprehensive control, fault diagnosis, prospecting, and other research fields $[14,15]$.

3.1. Basic Concepts. Suppose a frame of discernment $H=$ $\left\{H_{1}, H_{2}, \ldots, H_{N}\right\}$, which is a set of all possible results of a certain question. Shafer thought that the selection of $H$ depended on people's knowledge and understanding level, and the elements in $H$ were independent and should contain all possible results.

Shafer gave a new explanation of probability constructive explanation. Namely, probability is the trust degree of people in a true proposition on the basis of evidence, referred to as the reliability. In his view, there were not certain objective contacts between a batch of given evidence and a given proposition that could determine a precise support; we cannot always use a fairly accurate real numbers to express a downto-earth person's psychological description of a proposition. The understanding of reliability to a proposition according to evidence can be illustrated in Figure 1.

Definition 1. Suppose a frame of the discernment $H$, if set function $m: 2^{\Theta} \rightarrow[0,1]\left(2^{\Theta}\right.$ is the power set of $\left.\Theta\right)$ satisfies (1) $m(\phi)=0 ;(2) \sum_{A c \Theta} m(A)=1$.

One calls $m$ as the basic probability assignment on frame $\Theta$. When $A \subset \Theta, m(A)$ is called the basic probability number of $A$; When $A=\Theta, m(A)$ refers to the part of the reliability that does not know how to allocate.

The basic probability number reflects the size of the reliability of $A$ itself. Condition (1) reflects that it does not produce any reliability for empty set (empty proposition). Condition (2) reflects that although one can give a proposition to a reliability value of any size, one has to subject to the constraints that the sum of the reliability value of all propositions is equal to 1 ; that is, the total reliability is 1 .

Definition 2. Suppose that a frame of the discernment $H, m$ : $2^{\Theta} \rightarrow[0,1]$ is the basic probability assignment on frame $H$; then, one calls function Bel : $2^{\Theta} \rightarrow[0,1]$ which is defined by $\operatorname{Bel}(A)=\sum_{B \subset A} m(B)(\forall A \subset \Theta)$ as the reliability function on $\Theta$.

3.2. Synthesis Principle. The following is Dempster synthesis principle, which has the most application value in evidence theory.

Theorem 3. Suppose that $\mathrm{Bel}_{1}, \mathrm{Bel}_{2}, \ldots, \mathrm{Bel}_{n}$ are the reliability functions on the same frame of discernment $H, m_{1}, m_{2}, \ldots, m_{n}$ are the corresponding basic probability assignments, if $\mathrm{Bel}_{1} \oplus$ $\mathrm{Bel}_{2} \oplus \cdots \oplus \mathrm{Bel}_{n}$ exists, and the basic probability assignment is $m$; then,

$$
\forall A \subset \Theta, \quad A \neq \phi,
$$

$$
m(A)=K \cdot \sum_{\substack{A_{1}, \ldots, A_{n} \subset \Theta \\ A_{1} \cap \cdots \cap A_{n}=A}} m_{1}\left(A_{1}\right) \cdots m_{n}\left(A_{n}\right) .
$$

Among which,

$$
K=\left(\sum_{\substack{A_{1}, \ldots, A_{n} \subset \Theta \\ A_{1} \cap \cdots \cap A_{n} \neq \phi}} m_{1}\left(A_{1}\right) \cdots m_{n}\left(A_{n}\right)\right)^{-1} .
$$

Or

$$
K=\left(1-\sum_{\substack{A_{1}, \ldots, A_{n} \subset \Theta \\ A_{1} \cap \cdots \cap A_{n}=\phi}} m_{1}\left(A_{1}\right) \cdots m_{n}\left(A_{n}\right)\right)^{-1}
$$

This formula is the Dempster principle which is synthesized by multiple reliability functions.

\section{The Application of $D-S$ Theory in the City Emergency Capability Evaluation}

The city emergency capability is a complex and comprehensive problem which includes multiple indexes. When evaluating a city, we should not only consider the existence of the objective evidence of city emergency capability but also the subjective factors caused by the insufficient evidence and personal knowledge and experience restrictions of evaluation experts. $D$-S theory is developing on the basis of considering these factors. Therefore, the application of $D-S$ theory in the city emergency capability evaluation is feasible and has its certain application value.

\subsection{The Description of the Problem}

Target Layer (E). Evaluation of city emergency capability.

Frame of Discernment. $H=\left\{H_{k} \mid k=1,2,3,4,5\right\}=$ \{Best, Good, Average, Poor, Worst $\}$.

Index System. $E=\left\{E_{i} \mid i=1,2, \ldots, n\right\}$, of which $E_{i}=\left\{E_{i j} \mid\right.$ $\left.j=1,2, \ldots, m_{i}\right\}, m_{i}$ means that the primary index $E_{i}$ has $m_{i}$ secondary indexes. The index system in this paper is as Table 1 and we will use the weight in the literature [5]. After the aggregation and unification, index weights of various levels are as follows:

$$
\begin{gathered}
w=\left\{w_{i} \mid i=1,2,3\right\}=\{0.3846,0.4381,0.1773\} ; \\
w_{1}=\{0.3193,0.2624,0.1368,0.2816\}
\end{gathered}
$$




$$
\begin{gathered}
w_{2}=\{0.2223,0.1678,0.3454,0.2646\} \\
w_{3}=\{0.5561,0.4439\}
\end{gathered}
$$

Evaluation experts $L=\left\{L_{q} \mid q=1,2, \ldots, s\right\}$.

Experts give the confidence $S_{i j, k}(i=1,2, \ldots, n ; j=$ $\left.1,2, \ldots, m_{i} ; k=1, \ldots, 5\right)$, among which $0 \leq S_{i j, k} \leq 1$ and $\sum_{k=1}^{5} S_{i j, k} \leq 1$, to get the evaluation $H_{k}$ under the secondary index $E_{i j}$ of a city on the basis of objective evidence according to their own knowledge, experience, personal preference, and so forth.

4.2. Calculation Steps. First of all, establish the mass function of secondary indexes according to the confidence $S_{i j, k}$ and the secondary index weights given by experts. The specific method is to suppose that the index with the maximum weight in secondary indexes is the key index, while the rest are nonkey indexes. Suppose that the key index is $E_{i q}$ and its weight is $w_{i q}$, and then, the mass function is

$$
\begin{gathered}
m\left(E_{i q} \mid H_{k}\right)=\alpha \cdot S_{i j, k} \\
m\left(E_{i q} \mid H_{\Theta}\right)=1-\sum_{k=1}^{5} m\left(E_{i q} \mid H_{k}\right) .
\end{gathered}
$$

Suppose that the nonkey index is $w_{i t}$; then, the corresponding mass function is

$$
\begin{gathered}
m\left(E_{i t} \mid H_{k}\right)=\left(\frac{w_{i t}}{w_{i q}}\right) \alpha \cdot S_{i j, k} ; \\
m\left(E_{i t} \mid H_{\Theta}\right)=1-\sum_{k=1}^{5} m\left(E_{i t} \mid H_{k}\right),
\end{gathered}
$$

among which $\alpha$ is the discount coefficient and its value range is $(0,1]$ and let $\alpha=0.9$ in this paper. Due to the different weights of different indexes, the supporting strengths on the higher level index produced by their confidences are different. For instance, suppose that there are two secondary indexes $E_{i 1}$ and $E_{i 2}$ under the primary index $E_{i}$ and their relative weights $w_{i 1}>w_{i 2}$. Expert $L$ gives the same confidence $\beta_{i 1}=$ $\beta_{i 2}$ to the city $\mathrm{A}$. Then, it is obvious that the supporting strength produced by $\beta_{i 1}$ is greater than that produced by $\beta_{i 2}$ on the primary index $E_{i}$, although the confidence $\beta_{i 1}=\beta_{i 2}$. Thus, we set the key index as the benchmark to which other indexes can refer. Discount coefficient reflects the extent to which the key index and nonkey indexes can support the higher level index.

Secondly, according to the Dempster principle, namely, $m(A)=K \cdot \sum_{A_{1}, \ldots, A_{n} \subset \Theta, A_{1} \cap \cdots \cap A_{n}=A} m_{1}\left(A_{1}\right), \ldots, m_{n}\left(A_{n}\right)$, we will get a mass function of the experts on the primary index after synthesizing the mass function of the two indicators. According to the weight of the primary index, we will use the weighting method to calculate the evaluation of target layers of this city.

Thirdly, we will make Dempster synthesize on experts, that is, a concentrative process of the opinions of experts, to obtain the total evaluation of target layers of this city.
Finally, we quantize the frame of discernment, that is, to determine the evaluation value of the comments using the ratio scale method. Here, we will make the following values: $P(H)=\left\{P\left(H_{1}\right), P\left(H_{2}\right), P\left(H_{3}\right), P\left(H_{4}\right), P\left(H_{5}\right)\right\}=\{0.9$, $0.7,0.5,0.3,0.1\}$. So, we will get the final evaluation value of the city emergency capacity.

\section{Example Analysis}

This section uses a specific example to illustrate the effectiveness and practicality of city emergency capability evaluation with the application of evidence theory. Setting a certain city in China as an evaluation object, we invite three experts to evaluate them. Table 2 shows the initial evaluation datum of the city by experts $X, Y$, and $Z$. According to the initial datum, we construct the mass function of secondary indexes, that is, we carry out the calculation based on the key index, nonkey indexes, and discount coefficient.

The results of the first synthesis of the secondary indexes in the evaluation index system according to the synthesis principle of the $D-S$ theory are shown in Table 3.

According to the weight of the primary indexes, namely, $w=\left\{w_{i} \mid i=1,2,3\right\}=\{0.3846,0.4381,0.1773\}$, we use the weight method to calculate the evaluation of the city target layer. Then, base on the weight and use the weight method to calculate the evaluation of the city target layer. The results are shown in Table 4.

The weights of the three experts $X, Y$, and $Z$ are, respectively, $0.2,0.5$, and 0.3 . Then, Dempster synthesize three experts $X, Y$, and $Z$ according to the Dempster synthesis principle, that is, a concentrative process of the opinions of experts, to obtain the total evaluation of three experts. The results are shown in Table 5.

Finally, according to the ratio scale method mentioned above, namely, $P(H)=\left\{P\left(H_{1}\right), P\left(H_{2}\right), P\left(H_{3}\right), P\left(H_{4}\right)\right.$, $\left.P\left(H_{5}\right)\right\}=\{0.9,0.7,0.5,0.3,0.1\}$, we obtain the final evaluation value after the calculation, so the final result of the city emergency response capacity is 0.6447 .

From the calculation procedure and the results above, we can find out the bottleneck in city emergency capability construction through city emergency capability evaluation based on evidence theory. For example, the initial datum given by experts is the different trust degrees of the secondary indexes in city emergency capability evaluation. Through a Dempster synthesis, we can know the evaluation of the primary index. In addition, the synthetic process also takes into account the evaluation that cannot be given due to uncertainty. Focusing on improving the bottleneck with lower scores, we can enhance and improve the city emergency capability construction faster and better, so as to minimize the harm caused by disasters and emergencies.

\section{Conclusion}

The evidence theory is a decision-making method used to solve information-complex and uncertain problems, and the application of evidence theory in city emergency capability evaluation has its feasibility and superiority. This paper 
TABLE 2: The initial evaluation datum of the city table by experts $X, Y$, and $Z$.

\begin{tabular}{ccccc}
\hline The primary index & The secondary indexes & $X$ & $Y$ & $Z$ \\
\hline & $E_{11}$ & $H_{2}(0.7) H_{3}(0.1) H_{4}(0.2)$ & $H_{2}(0.7) H_{3}(0.2) H_{4}(0.1)$ & $H_{2}(0.6) H_{3}(0.3) H_{4}(0.1)$ \\
$E_{1}$ & $E_{12}$ & $H_{2}(0.5) H_{3}(0.4) H_{4}(0.1)$ & $H_{2}(0.8) H_{3}(0.2) H_{4}(0)$ & $H_{2}(0.5) H_{3}(0.2) H_{4}(0.3)$ \\
& $E_{13}$ & $H_{2}(0.2) H_{3}(0.6) H_{4}(0.2)$ & $H_{2}(0.9) H_{3}(0.1) H_{4}(0)$ & $H_{2}(0.8) H_{3}(0.1) H_{4}(0.1)$ \\
& $E_{14}$ & $H_{2}(0.4) H_{3}(0.4) H_{4}(0.3)$ & $H_{2}(0.8) H_{3}(0.2) H_{4}(0)$ & $H_{2}(0.4) H_{3}(0.4) H_{4}(0.2)$ \\
& $E_{21}$ & $H_{2}(0.5) H_{3}(0.4) H_{4}(0.1)$ & $H_{2}(0.6) H_{3}(0.2) H_{4}(0.2)$ & $H_{2}(0.7) H_{3}(0.2) H_{4}(0.1)$ \\
& $E_{22}$ & $H_{2}(0.4) H_{3}(0.5) H_{4}(0.1)$ & $H_{2}(0.8) H_{3}(0.2) H_{4}(0)$ & $H_{2}(0.8) H_{3}(0.1) H_{4}(0.1)$ \\
& $E_{23}$ & $H_{2}(0.1) H_{3}(0.2) H_{4}(0.7)$ & $H_{2}(0.8) H_{3}(0.2) H_{4}(0)$ & $H_{2}(0.6) H_{3}(0.2) H_{4}(0.2)$ \\
$E_{2}$ & $E_{24}$ & $H_{2}(0.2) H_{3}(0.4) H_{4}(0.4)$ & $H_{2}(0.7) H_{3}(0.1) H_{4}(0.2)$ & $H_{2}(0.7) H_{3}(0.1) H_{4}(0.2)$ \\
& $E_{31}$ & $H_{2}(0.2) H_{3}(0.6) H_{4}(0.2)$ & $H_{2}(0.7) H_{3}(0.1) H_{4}(0.2)$ & $H_{2}(0.6) H_{3}(0.2) H_{4}(0.2)$ \\
& $E_{32}$ & $H_{2}(0.3) H_{3}(0.4) H_{4}(0.3)$ & $H_{2}(0.6) H_{3}(0.4) H_{4}(0)$ & $H_{2}(0.6) H_{3}(0.3) H_{4}(0.1)$ \\
\hline
\end{tabular}

TABLE 3: The primary index evaluation of the city by experts $X, Y$, and $Z$.

\begin{tabular}{ccccc}
\hline General goal & The primary index & $X$ & $Y$ & $Z$ \\
\hline \multirow{2}{*}{$E_{1}$} & $H_{2}(0.7147) H_{3}(0.1594)$ & $H_{2}(0.9430) H_{3}(0.0452)$ & $H_{2}(0.7319) H_{3}(0.1847)$ \\
& $H_{4}(0.1115) H_{\Theta}(0.0144)$ & $H_{4}(0.0056) H_{\Theta}(0.0062)$ & $H_{4}(0.0708) H_{\Theta}(0.0126)$ \\
$E$ & $H_{2}(0.1568) H_{3}(0.3209)$ & $H_{2}(0.9121) H_{3}(0.0604)$ & $H_{2}(0.8550) H_{3}(0.0620)$ \\
& & $H_{4}(0.4914) H_{\Theta}(0.0309)$ & $H_{4}(0.0126) H_{\Theta}(0.0149)$ & $H_{4}(0.0663) H_{\Theta}(0.0167)$ \\
& $E_{3}$ & $H_{2}(0.1894) H_{3}(0.5731)$ & $H_{2}(0.7560) H_{3}(0.1228)$ & $H_{2}(0.6708) H_{3}(0.1741)$ \\
& $H_{4}(0.1894) H_{\Theta}(0.0480)$ & $H_{4}(0.0779) H_{\Theta}(0.0433)$ & $H_{4}(0.1110) H_{\Theta}(0.0441)$ \\
\hline
\end{tabular}

TABLE 4: Emergency capability evaluation of the city.

\begin{tabular}{lcc}
\hline Target layer & Expert & Synthesis results \\
\hline & $X$ & $H_{2}(0.3771) H_{3}(0.3035)$ \\
& & $H_{4}(0.2917) H_{\Theta}(0.0276)$ \\
& $Y$ & $H_{2}(0.8963) H_{3}(0.0656)$ \\
& $H_{4}(0.0215) H_{\Theta}(0.0166)$ \\
& $H_{2}(0.7750) H_{3}(0.1291)$ \\
& $Z$ & $H_{4}(0.0760) H_{\Theta}(0.0200)$ \\
\hline
\end{tabular}

TABLE 5: The city's evaluation of the target layer by three experts.

\begin{tabular}{lc}
\hline General goal & Synthesis results \\
\hline City emergency & $H_{2}(0.8736) H_{3}(0.0520)$ \\
Capability & $H_{4}(0.0240) H_{\Theta}(0.0505)$ \\
\hline
\end{tabular}

proposes to use evidence theory to evaluate city emergency capacity on the basis of the existing evaluation system and then shows that it has practical value with the combination of an example. If we let experts to evaluate the emergency capability of a certain city, it is difficult to give a specific evaluation value. We allocate the city emergency capability evaluation into a number of small indexes, and experts only need to score these specific, detailed evaluation indexes. And when scoring each secondary index, experts give the trust degrees of different evaluation ranks, including the trust degrees that cannot be given, so as to better reflect the uncertainty due to evidence confusion or incompletion. In the future, we will research key evaluation index and auxiliary evaluation index of different stages and different institutions, and using different evaluation theories and methods, we will evaluate the typical regional government emergency capability and the main disaster accident emergency capability.

\section{Acknowledgments}

This paper was partially supported by the National Natural Science Foundation of China (NSFC) (Grant no. 71201093), Humanities and Social Sciences Foundation of Ministry of Education of China (Grant no. 10YJCZH217), Promotive Research Fund for Excellent Young and Middle-Aged Scientists of Shandong Province (Grant no. BS2012SF012), and Independent Innovation Foundation of Shandong University, (IIFSDU) (Grant no. 2012TS194).

\section{References}

[1] Emergency Support Function Annexes: Introduction, http:// www.fema.gov/pdf/emergency/nrf/nrf-esf-intro.pdf.

[2] The Japanese disaster emergency system for reference, http:// www.csstoday.net/Item.aspx?id=5261.

[3] Y. Deng, S. Zheng, and T. Liu, "Review of disaster capability assessment and emergency system," China Journal of Safety Science and Technology, vol. 1, no. 5, pp. 56-58, 2005 (Chinese).

[4] Y. Deng, S. Zheng, G. Liu, and T. Liu, "Study on city emergency capability assessment system," China Journal of Safety Science and Technology, no. 12, pp. 33-36, 2005 (Chinese).

[5] J. Zhang, X. Zheng, and J. Peng, "Research on emergency capacity evaluation based on fuzzy analytic hierarchy process," Safety and Environmental Engineering, vol. 14, no. 3, pp. 80-82, 2007 (Chinese).

[6] L. Cheng, S. Li, and H. Lin, "Establishment of assessment index system for the emergency capability of the coal mine based on SEM," Procedia Engineering, vol. 26, pp. 2313-2318, 2011. 
[7] X.-T. Wu and L.-P. Wu, "Evaluation of the fire emergency rescue capability in urban community," Procedia Engineering, vol. 11, pp. 536-540, 2011.

[8] Z. Wang, B. Wang, and H. Zhang, "Research on urban emergency capability evaluation based on logistic curve," China Safety Science Journal, vol. 21, no. 3, pp. 163-169, 2011 (Chinese).

[9] D. M. Simpson, Building Neighborhood and Local Emergency Capability: The Role of Community-Based Disaster Preparedness Programs, University of California, Berkeley, Calif, USA, 1997.

[10] J. S. Simonoff, C. E. Restrepo, R. Zimmerman, Z. S. Naphtali, and H. H. Willis, "Resource allocation, emergency response capability, and infrastructure concentration around vulnerable sites," Journal of Risk Research, vol. 14, no. 5, pp. 597-613, 2011.

[11] Y. Ju, A. Wang, and X. Liu, "Evaluating emergency response capacity by fuzzy AHP and 2-tuple fuzzy linguistic approach," Expert Systems with Applications, vol. 39, no. 8, pp. 6972-6981, 2012.

[12] G. Shafer, A mathematical Theory of Evidence, Princeton University Press, Princeton, NJ, USA, 1976.

[13] J. Kacprzyk, Studies in Fuzziness and Soft Computing, Springer, Berlin, Germany, 2008.

[14] M. Shoyaib, M. Abdullah-Al-Wadud, and O. Chae, "A skin detection approach based on the Dempster-Shafer theory of evidence," International Journal of Approximate Reasoning, vol. 53, no. 4, pp. 636-659, 2012.

[15] M. A. Boujelben, Y. de Smet, A. Frikha, and H. Chabchoub, "A ranking model in uncertain, imprecise and multi-experts contexts: the application of evidence theory," International Journal of Approximate Reasoning, vol. 52, no. 8, pp. 1171-1194, 2011. 


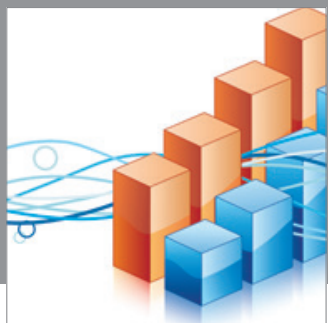

Advances in

Operations Research

mansans

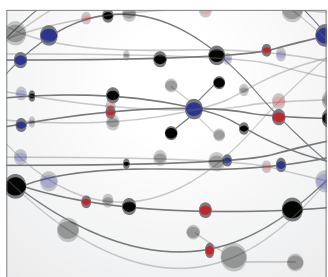

The Scientific World Journal
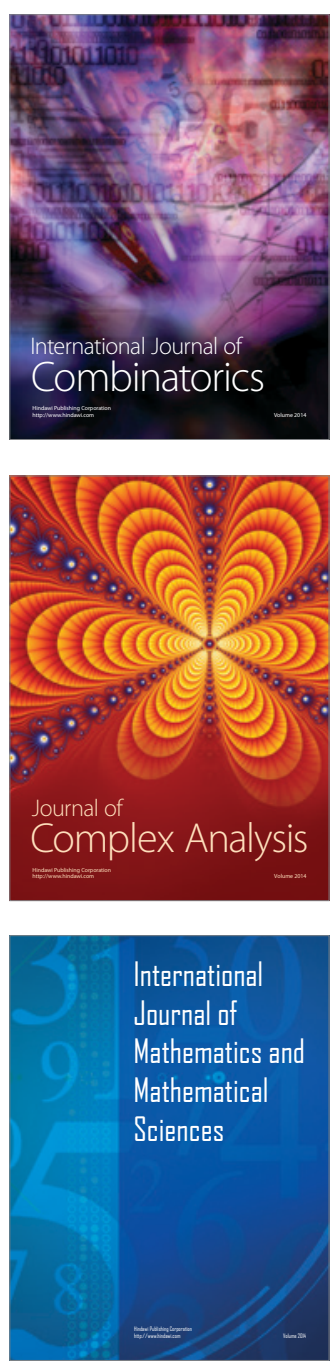
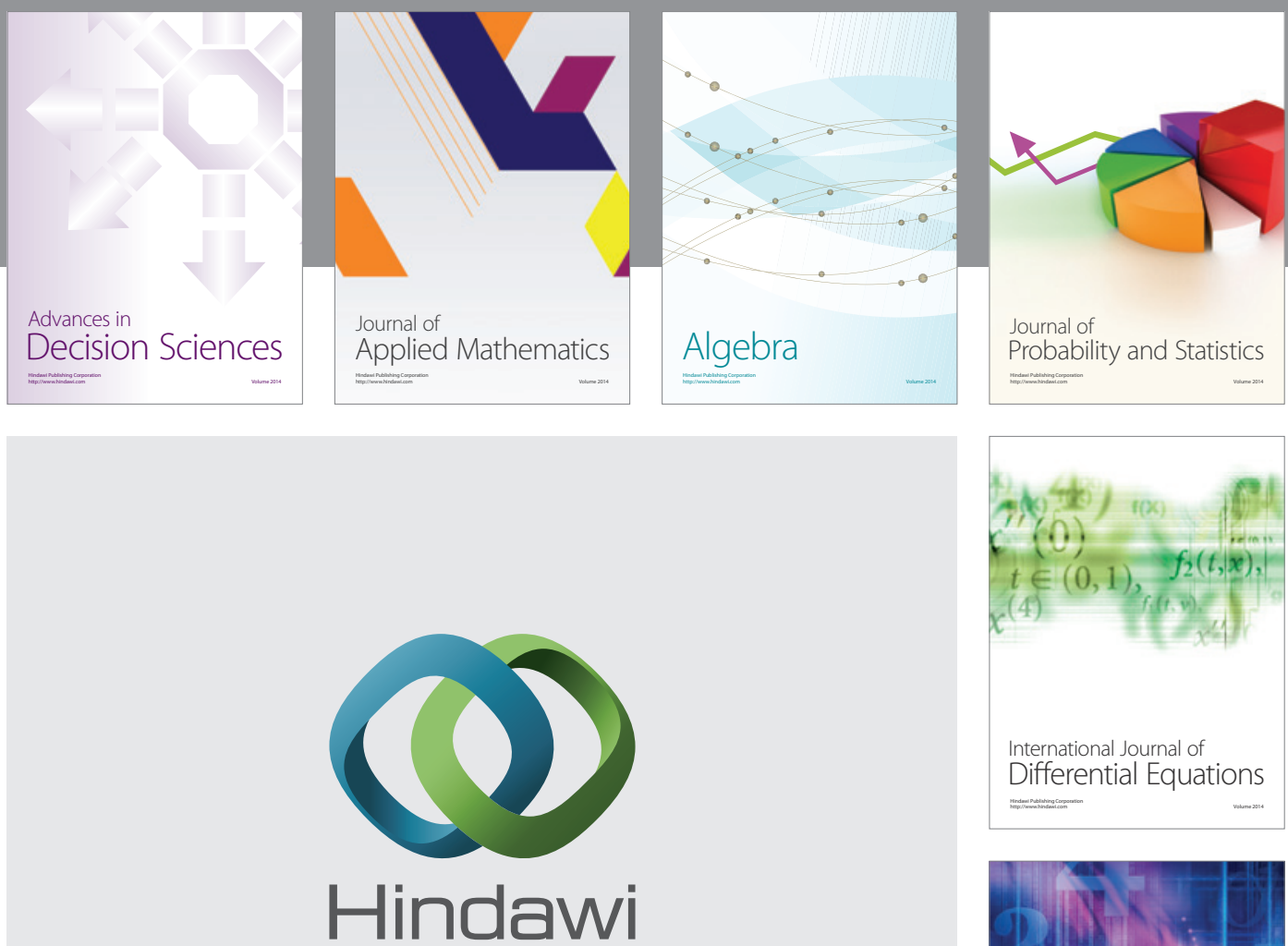

Submit your manuscripts at http://www.hindawi.com
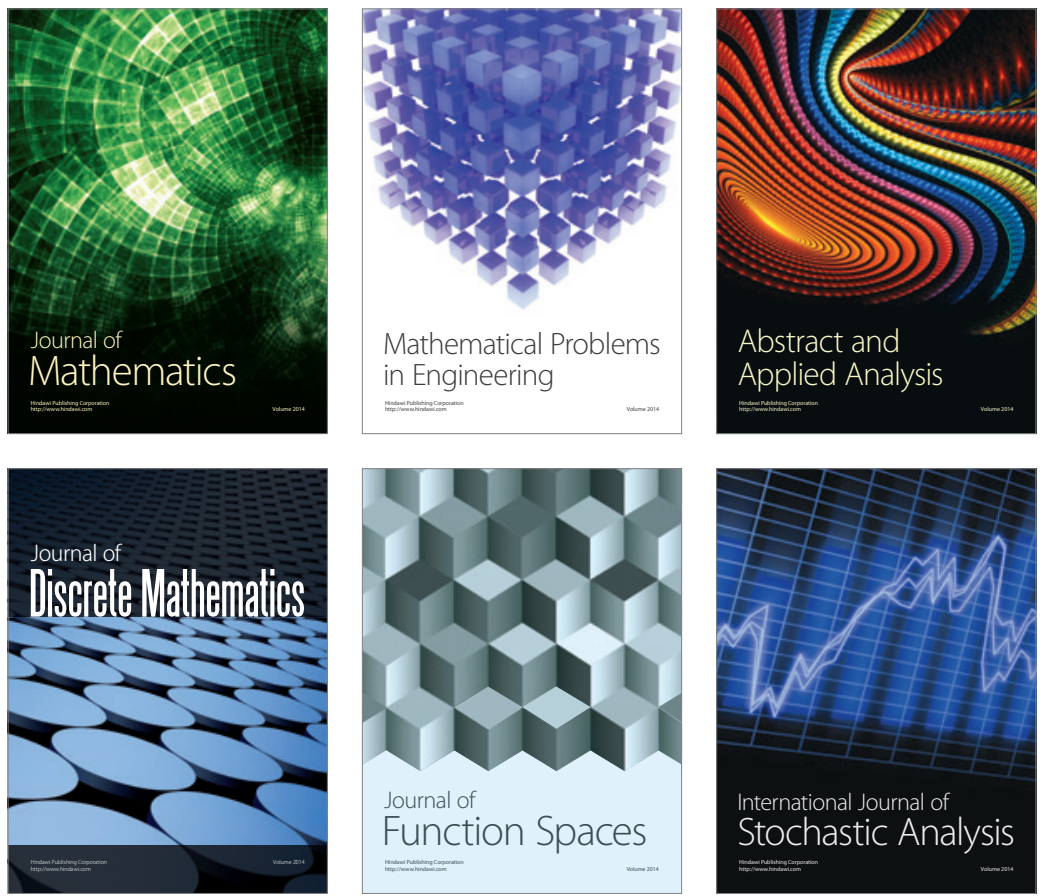

Journal of

Function Spaces

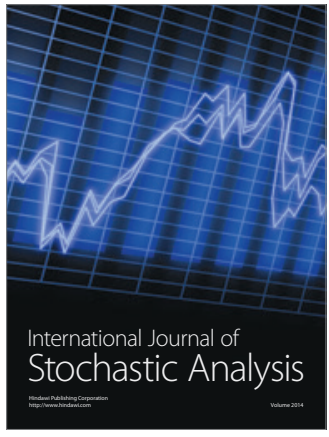

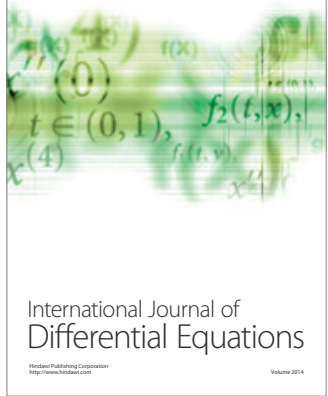
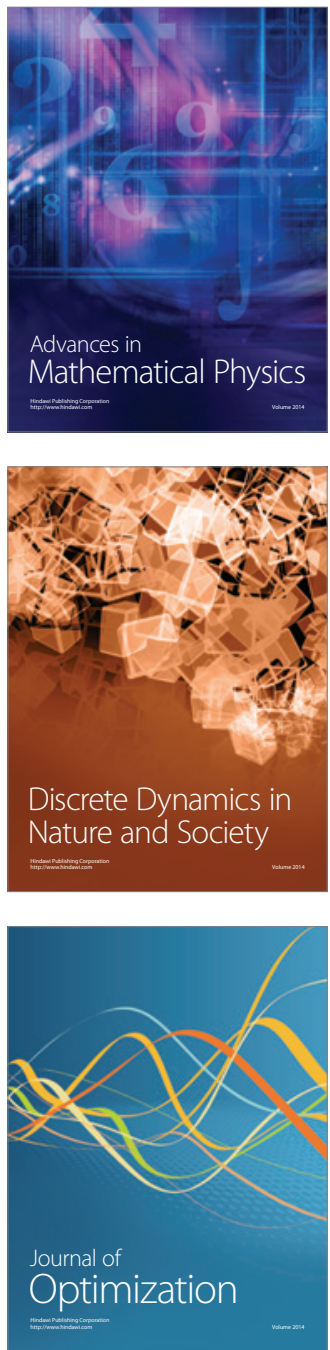